\title{
IMPLEMENTASI METODE WEIGHT PRODUCT BERBASIS WEBSITE UNTUK REKOMENDASI BENTUK STEMPEL RUNAFLEK (Studi Kasus: Toko Stempel Rahmad Jaya Dusun Jiwut Kecamatan Nglegok Kabupaten Blitar)
}

\author{
Irviana Nuril Hidayah, Sri Lestanti, Sabitul Kirom \\ Program Studi Teknik Informatika S1, Fakultas Teknologi Informasi \\ Universitas Islam Balitar, Jalan Majapahit Blitar, Indonesia \\ irviana.nuril@gmail.com
}

\begin{abstract}
ABSTRAK
Stempel merupakan sebuah kerajinan tangan yang terbuat dari kayu waru dan ada juga yang terbuat dari plastik. Berdasarkan survei lapangan didapatkan hasil bahwa di daerah Desa Jiwut kebanyakan berprofesi sebagai pengrajin stempel runaflek, sehingga peneliti akan membuat sistem tentang kendala dalam penjualan stempel di Toko yang dipilih. Toko stempel runaflek ini terdapat beberapa kendala yang dihadapi khususnya dalam pemilihan bentuk dan ukuran stempel. Di toko stempel runaflek ini tidak terdapat sistem atau aplikasi untuk merekomendasikan bentuk dan ukuran sebuah stempel. Cara ini membutuhkan waktu relatif lama. Maka dari itu, perusahaan stempel ini membutuhkan suatu aplikasi pendukung keputusan yang dapat merekomendasikan bentuk dan ukuran stempel berdasarkan kriteria dari customer sehingga dapat membantu sistem kerja pada perusahaan stempel runaflek agar lebih efektif. Aplikasi yang dibuat menggunakan metode Weight Product berbasis website. Pada metode ini ada berbagai alur yang harus dihitung sebelum menyimpulkan hasil perangkingan dengan benar, yaitu menentukan beberapa bobot kriteria, setelah itu membuat aplikasi dengan menggunakan framework codeigniter. Hasil penelitian kemudian diuji menggunakan metode Blackbox Testing. Selanjutnya dilakukan pengujian aplikasi terhadap pengguna dan 2 Dosen Teknik Informatika. Pada pengujian Blacbox Testing menghasilkan angka $100 \%$. Selanjutnya hasil pengujian terhadap pengguna dan 2 dosen Teknik Informatika menghasilkan hasil presentase $50 \%$ yang berarti netral dan $40 \%$ yang berarti setuju.
\end{abstract}

Kata kunci : Stempel, Weight Product, Blackbox Testing, Framework Codeigniter

\section{PENDAHULUAN}

Stempel merupakan sebuah kerajinan tangan yang terbuat dari kayu waru dan ada juga yang terbuat dari plastik. Stempel karet merupakan salah satu kerajinan yang terkenal di Indonesia, yang mana ada bermacammacam jenis pewarna atau tinta yang diaplikasikan pada gambar atau suatu pola yang sudah dicetak menggunakan laser dan diaplikasikan pada selembar karet. Karet tersebut dipasang pada benda yang lebih stabil seperti plastik, kayu, batu akrilik atau batubata. Hasil cap stempel dapat digunakan untuk pengesahan berkas penting, berupa surat resmi, pengesahan ijazah, nota, tanda terima kasih atau sebagai tanda pengesahan pelunasan.

Berdasarkan hasil penelitian dan survei di lapangan didapatkan hasil bahwa di daerah Desa Jiwut kebanyakan berprofesi sebagai pengrajin stempel runaflek, sehingga peneliti akan membuat sistem tentang kendala dalam penjualan stempel di Toko yang dipilih. Toko stempel runaflek ini terdapat beberapa kendala yang dihadapi khususnya dalam pemilihan bentuk dan ukuran stempel. Di toko stempel runaflek ini tidak terdapat sistem untuk merekomendasikan bentuk dan ukuran sebuah stempel. Cara ini membutuhkan waktu relatif lama. Maka dari itu, perusahaan stempel ini membutuhkan suatu aplikasi pendukung keputusan yang dapat merekomendasikan bentuk dan ukuran stempel berdasarkan kriteria dari customer sehingga dapat membantu sistem kerja pada perusahaan stempel runaflek agar lebih cepat dan mudah. Adapun kelebihan dari sistem ini adalah menggunakan metode Weight Product yang mempunyai kelebihan yaitu perhitungannya tidak begitu kompleks sehingga mudah dipahami dan juga terdapat variabel biaya dan keuntungan, yang bermanfaat untuk menentukan hasil akhir terhadap suatu putusan, selain dapat mengetahui rekomendasi bentuk dan ukuran stempel sistem ini juga dapat memberikan total harga hasil akhirnya, jadi lebih mudah dan efisien.

Berikut ini merupakan batasan dalam penelitian yang dikemukakan oleh penulis:

a. Kriteria yang ditentukan adalah tingkat kepentingan waktu dalam perusahaan, harga stempel, kerumitan dan warna cat pada stempel tersebut.

b. Bentuk stempel yang direkomendasikan yaitu stempel bulat, stempel polos, stempel kotak dan stempel oval.

c. Rekomendasi bentuk dan ukuran stempel untuk jenis stempel runaflek atau stempel kayu.

d. Pengguna yang akan memakai adalah pengguna yang mengalami kesulitan dalam pemilihan bentuk dan ukuran stempel untuk perusahaannya.

e. Pembuatan aplikasi menggunakan Codeigniter 3 dan database MySQL.

\section{TINJAUAN PUSTAKA}

\subsection{Kajian Penelitian}

Tahun 2020, Noviantoro melakukan sebuah penelitian tentang Penentuan Tarif Jasa Lukis Dengan Menerapkan Metode AHP. Data A(i) yang digunakan pada penilitian ini merupakan beberapa lukisan yang sering dipesan oleh pelanggan dengan persentase kesalahan sebesar 25\% dimana tarif yang di tujukan memiliki selisih harga lebih sedikit Rp 25.000,00 dari tarif yang ditentukan kala itu. Aplikasi yang sudah rampung selanjutnya akan dites dengan menggunakan metode blackbox testing untuk menguji keefektifan tombol dan 
fitur pada aplikasi dengan perolehan nilai sebesar $100 \%$ [1].

\subsection{Sistem Pendukung Keputusan}

Sistem Pendukung Keputusan (SPK) merupakan sistem yang ditujukan untuk menunjang pengambilan putusan. Ada 3 pembagian ketika pemrosesan pengambilan keputusan di antaranya adalah: [2]

1. Intelligence

Intelligence adalah sebuah pencarian status yang mampu mengangkat kesimpulan.

2. Desain

Desain adalah memaparkan sebuah objek untuk diselesaikan.

3. Pilihan

Pilihan adalah pemilihan dari berbagai objek yang jelas dan perolehan tersebut akan ditetapkan sebagai penetap pada keputusan.

\subsection{Codeigniter}

CodeIgniter adalah sebuah framework PHP yang sifatnya terbuka dan menggunakan metode MVC (Model, View, Controller) yang bertujuan untuk mendukung dan memudahkan dalam mengembangkan suatu aplikasi yang berbasis website tanpa harus membuatnya dari nol [3].

\section{METODE PENELITIAN}

\subsection{Ruang Lingkup Penelitian}

Observasi yang dilakukan ini berlokasi di Kota Blitar lebih tepatnya di Desa Jiwut Kecamatan Nglegok. Desa Jiwut terkenal dengan berbagai pekerjaan pembuat kerajinan. Pekerjaan kerajinan ini ada beberapa jenis yaitu pengrajin kendang, pengrajin yoyo, pengrajin skak dan juga pengrajin stempel. Salah satu kerajinan yang paling aktif yaitu kerajinan stempel runaflek yang pengrajinnya sangat banyak. Bahan utama dari stempel runaflek ini cukup mudah ditemukan yaitu menggunakan bahan kayu waru.

\subsection{Jenis Penelitian}

Dalam penelitian ini, jenis penelitian yang digunakan oleh peneliti adalah penelitian pengembangan atau Research and Development (R\&D). (R\&D) merupakan suatu metode penelitian yang dipakai untuk membuat sistem tertentu, dan mengevaluasi kegunaan sistem yang dibuat.

\subsection{Jenis Data}

a. Data Primer

Data primer yang digunakan adalah daftar bentuk stempel, ukuran stempel serta harga stempel runaflek di Toko Rahmad Jaya.

b. Data Sekunder

Data sekunder didapatkan oleh peneliti dengan mengumpulkan data oleh pihak ketiga yang berupa pendapat para ahli. Data sekunder diperoleh dengan cara mengumpulkan sejumlah informasi dengan melakukan analisis media yang berkaitan dengan masalah.

\subsection{Instrumen Pengumpulan Data}

a. Metode Observasi

Teknik observasi mempunyai tujuan untuk mendapatkan sebuah pengetahuan yang luas. Dengan hal ini peneliti berhasil memperoleh data untuk bentuk stempel serta harga masing-masing stempel dengan ukuran tertentu. Dengan menggunakan metode observasi ini peneliti dapat mengetahui tentang data-data yang dibutuhkan untuk proses pembuatan program rekomendasi bentuk dan ukuran stempel runaflek.

b. Metode Wawancara

Metode ini merupakan mengumpulkan data-data informasi yang dilaksanakan dengan cara mewawancara secara tatap muka kepada pemilik usaha dengan mengemukakan beberapa kuesioner tentang penelitian yang akan dibuat peneliti yaitu rekomendasi bentuk dan ukuran stempel runaflek.

\subsection{Perancangan Sistem Aplikasi \\ 3.5.1 Flowchart Sistem Aplikasi}

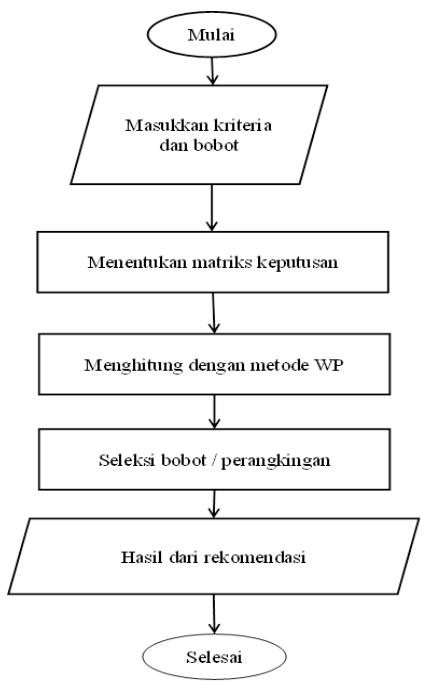

Gambar 1. Flowchart Sistem

Pada gambar 1 diatas, proses dimulai dari memasukkan beberapa kriteria dan bobot yang meliputi kepentingan dalam perusahaan, harga, kerumitan dan warna cat. Selanjutnya, menentukan matriks keputusan. Setelah itu, sistem akan menghitung matriks keputusan tersebut dengan metode Weight Product dan menyeleksi atau melakukan perangkingan pada hasil tersebut. Lalu, sistem akan memunculkan hasil perangkingan berupa rekomendasi peringkat 1 , peringkat 2 dan seterusnya. 


\subsubsection{Flowchart Weight Product}

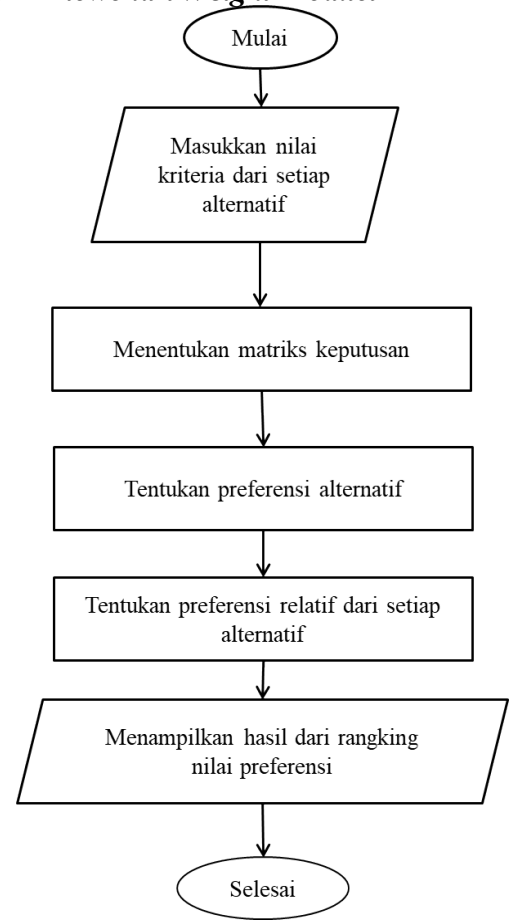

Gambar 2. Flowchart Weight Product

Pada gambar 2 proses dimulai dari menentukan nilai-nilai dari setiap alternatif. Kemudian, menentukan matriks keputusan. Setelah itu, menentukan preferensi alternatif dengan rumus yang sudah ditentukan. Selanjutnya, menentukan preferensi relative dari setiap alternatif dan yang terakhir menampilkan hasil rangking dari nilai preferensi.

\subsubsection{Data Flow Diagram level 0}

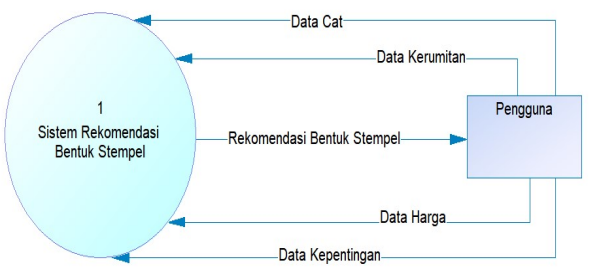

Gambar 3. Data Flow Diagram level 0

Pada gambar 3 yang merupakan Data Flow Diagram level 0 yang dijelaskan bahwa pengguna akan menginputkan data cat, data kerumitan, data harga, dan data kepentingan. Kemudian, jika semua data sudah masuk maka sistemnya akan mengembalikan hasil rekomendasi berupa perangkingan rekomendasi stempel.

\subsubsection{Data Flow Diagram Level 1}

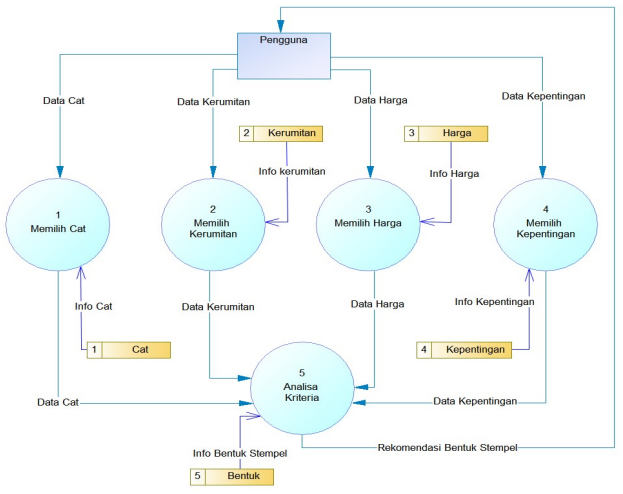

Gambar 4. Data Flow Diagram level 1

Gambar 4 menunjukkan gambar tahapan lebih lanjut tentang DFD level 0, dimana semua proses yang ada pada DFD level 0 akan dirinci lebih lengkap dan jelas sehingga lebih detail.

\subsubsection{Entity Relational Diagram (ERD)}
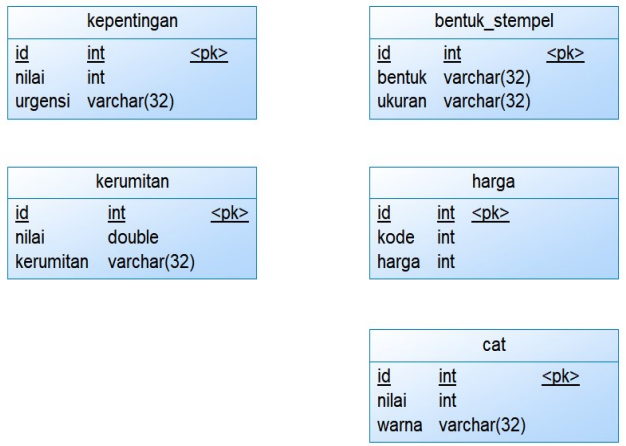

Gambar 5. Entity Relational Diagram (ERD)

Pada gambar 5 di atas merupakan Entity Relational Diagram (ERD) dari aplikasi sistem. Pada ERD tersebut terdapat 5 tabel yaitu tabel kepentingan, tabel kerumitan, tabel bentuk stempel, tabel harga dan tabel cat.

\subsection{Rekapitulasi Weight Product}

3.6.1 Bobot Kriteria Sistem

Perhitungan dengan metode Weight Product adalah dengan memberikan nilai bobot pada setiap kriteria. Nilai bobot menunjukkan rating kepentingan. Bobot kriteria ditetapkan oleh perusahaan. Bobot kriteria dapat dilihat pada tabel 1 di bawah ini.

Tabel 1. Bobot Kriteria Sistem

\begin{tabular}{|l|c|c|}
\hline \multicolumn{1}{|c|}{ Kriteria } & Bobot & Kode \\
\hline $\begin{array}{l}\text { Kepentingan Waktu dalam } \\
\text { Perusahaan }\end{array}$ & 3 & $\mathrm{C} 1$ \\
\hline Harga & 5 & $\mathrm{C} 2$ \\
\hline Kerumitan & 2 & $\mathrm{C} 3$ \\
\hline Warna Cat & 2 & $\mathrm{C} 4$ \\
\hline Jumlah & $\mathbf{1 2}$ & \\
\hline
\end{tabular}


3.6.2 Tabel Hasil Perhitungan Normalisasi Bobot

Setelah menentukan bobot dari kriteria maka selanjutnya bobot tersebut dinormalisasikan dengan cara bobot dibagi dengan jumlah bobot tersebut dan nanti hasilnya seperti tabel 2 di bawah ini.

Tabel 2. Bobot Normalisasi

\begin{tabular}{|c|c|c|c|c|}
\hline Bobot & C1 & C2 & C3 & C4 \\
\hline $\begin{array}{c}\text { Bobot } \\
\text { Normalisasi }\end{array}$ & 0.25 & 0.42 & 0.17 & 0.17 \\
\hline
\end{tabular}

3.6.3 Kepentingan Waktu dalam Perusahaan

Pada kriteria kepentingan waktu dalam perusahaan dihitung berdasarkan waktu lamanya pembuatan, jika keterangan lambat dengan waktu estimasi pengerjaan 1 hari maka harga akan ditambahkan dengan harga Rp. 4.000, jika keterangan sedang dengan waktu estimasi pengerjaan 6 jam maka ditambahkan dengan harga Rp. 7.000 dan jika keterangan cepat dengan waktu estimasi pengerjaan 2 jam maka akan ditambahkan dengan harga $\mathrm{Rp}$. 10.000. Kriteria waktu dalam perusahan diberikan nilai sebagai berikut.

Tabel 3. Kepentingan Waktu dalam Perusahaan

\begin{tabular}{|l|c|}
\hline \multicolumn{1}{|c|}{ Keterangan } & Nilai kriteria \\
\hline Lambat $(1$ hari $)$ & 2 \\
\hline Sedang $(6$ jam $)$ & 3 \\
\hline Cepat $(2$ jam $)$ & 5 \\
\hline
\end{tabular}

\subsubsection{Kepentingan Harga}

Pada kriteria harga ditulis berdasarkan harga satuan model atau bentuk dengan ukuran yang sudah ditentukan dan pada kriteria harga diberikan hasil sebagai berikut.

Tabel 4. Kepentingan Harga

\begin{tabular}{|c|c|c|}
\hline Bentuk dan Ukuran & Kode & Harga \\
\hline Bulat $16 \mathrm{~mm}$ & $\mathrm{~A} 1$ & 12.000 \\
\hline Bulat $25 \mathrm{~mm}$ & $\mathrm{~A} 2$ & 14.000 \\
\hline Bulat $35 \mathrm{~mm}$ & $\mathrm{~A} 3$ & 16.000 \\
\hline Bulat $42 \mathrm{~mm}$ & $\mathrm{~A} 4$ & 17.000 \\
\hline Bulat $45 \mathrm{~mm}$ & $\mathrm{~A} 5$ & 20.000 \\
\hline Oval $30 * 43 \mathrm{~mm} \mathrm{OV} 45$ & $\mathrm{~A} 6$ & 20.000 \\
\hline Kotak $45 * 60 \mathrm{~mm}$ & $\mathrm{~A} 7$ & 20.000 \\
\hline Kotak $50 * 90 \mathrm{~mm}$ & $\mathrm{~A} 8$ & 20.000 \\
\hline Kotak $30 * 60 \mathrm{~mm}$ & $\mathrm{~A} 9$ & 20.000 \\
\hline Polos $12 \mathrm{~mm}$ & $\mathrm{~A} 10$ & 10.000 \\
\hline
\end{tabular}

\subsubsection{Kepentingan Kerumitan}

Pada kriteria kepentingan Kerumitan ditentukan berdasarkan kerumitan yang menjadi patokan. Kepentinga kerumitan dapat dilihat pada tabel 5 sebagai berikut.

Tabel 5. Tabel Kriteria Kerumitan

\begin{tabular}{|l|c|}
\hline \multicolumn{1}{|c|}{ Keterangan } & Nilai kriteria \\
\hline Tulisan Biasa (tidak rumit) & 2,5 \\
\hline Tanda Tangan (sedang) & 5,0 \\
\hline Logo (rumit) & 7,5 \\
\hline Arab (sangat rumit) & 10 \\
\hline
\end{tabular}

\subsubsection{Kepentingan Cat}

Pada kriteria kepentingan warna cat ada 3 warna yang di tentukan dari perusahaan yaitu warna kuning, warna merah, warna biru, warna hitam dan warna emas, warna-warna tersebut dihitung berdasarkan tahap pemrosesan yang nantinya setiap tahap akan ditambahkan dengan harga Rp. 1.000, dan pada kriteria kepentingan cat diberikan nilai sebagai berikut

Tabel 6. Tabel Kriteria Cat

\begin{tabular}{|l|c|}
\hline \multicolumn{1}{|c|}{ Keterangan } & Nilai Kriteria \\
\hline Kuning (2 proses) & 1 \\
\hline Biru (2 proses) & 2 \\
\hline Merah (2 proses) & 3 \\
\hline Hitam (2 proses) & 4 \\
\hline Emas (4 proses) & 5 \\
\hline
\end{tabular}

\subsubsection{Normalisasi Nilai pada Setiap Kriteria}

Pada tabel 7 dibawah ini dijelaskan rating kecocokan nilai 10 jenis stempel yang telah dimasukkan dan disesuaikan dalam range tiap kriteria yang telah ditentukan

Tabel 7. Normalisasi Nilai pada setiap Kriteria

\begin{tabular}{|c|c|c|c|c|}
\hline \multirow{2}{*}{ (Ai) } & \multicolumn{5}{|c|}{ Kriteria (Xj) } \\
\cline { 2 - 5 } & $\mathbf{C 1}$ & $\mathbf{C 2}$ & $\mathbf{C 3}$ & $\mathbf{C 4}$ \\
\hline V1 & 2 & 12.000 & 2.5 & 1 \\
\hline V2 & 3 & 14.000 & 5 & 3 \\
\hline V3 & 5 & 16.000 & 5 & 5 \\
\hline V4 & 3 & 17.000 & 7.5 & 3 \\
\hline V5 & 3 & 20.000 & 2.5 & 4 \\
\hline V6 & 5 & 25.000 & 2.5 & 3 \\
\hline V7 & 5 & 23.000 & 5 & 4 \\
\hline V8 & 3 & 45.000 & 10 & 5 \\
\hline V9 & 2 & 18.000 & 7.5 & 1 \\
\hline V10 & 5 & 12.000 & 2.5 & 2 \\
\hline
\end{tabular}

Kemudian normalisasi matriks keputusan (vector S) dan dapat dihitung sebagai berikut.

$\mathrm{S}_{1}=\left(2^{0,25}\right)\left(12.000^{0,42}\right)\left(2,5^{0,17}\right)\left(1^{0,17}\right) \quad=0.362472$

$\mathrm{S}_{2}=\left(3^{0,25}\right)\left(14.000^{0,42}\right)\left(5^{0,17}\right)\left(3^{0,17}\right) \quad=0.402487$

$\mathrm{S}_{3}=\left(5^{0,25}\right)\left(16.000^{0,42}\right)\left(5^{0,17}\right)\left(5^{0,17}\right) \quad=0.471100$

$\mathrm{S}_{4}=\left(3^{0,25}\right)\left(17.000^{0,42}\right)\left(7,5^{0,17}\right)\left(3^{0,17}\right) \quad=0.346952$

$\mathrm{S}_{5}=\left(3^{0,25}\right)\left(30.000^{0,42}\right)\left(2,5^{0,17}\right)\left(4^{0,17}\right) \quad=0.408511$

$\mathrm{S}_{6}=\left(5^{0,25}\right)\left(25.000^{0,42}\right)\left(2,5^{0,17}\right)\left(3^{0,17}\right) \quad=0.403147$

$\mathrm{S}_{7}=\left(5^{0,25}\right)\left(23.000^{0,42}\right)\left(5^{0,17}\right)\left(4^{0,17}\right) \quad=0.390125$

$\mathrm{S}_{8}=\left(3^{0,25}\right)\left(45.000^{0,42}\right)\left(10^{0,17}\right)\left(5^{0,17}\right) \quad=0.240032$

$\mathrm{S}_{9}=\left(2^{0,25}\right)\left(18.000^{0,42}\right)\left(7,5^{0,17}\right)\left(1^{0,17}\right) \quad=0.254908$

$\mathrm{S}_{10-}=\left(5^{0,25}\right)\left(12.000^{0,42}\right)\left(2,5^{0,17}\right)\left(2^{0,17}\right)=0.511601$

Setelah setiap nilai $\mathrm{V}(\mathrm{s})$ mendapatkan nilai akhir, tahap berikutnya adalah menjumlahkan seluruh nilai $\mathrm{V}(\mathrm{s})$ untuk menghitung nilai V(v). Perhitungannya sebagai berikut.

$\mathrm{V} 1=\frac{0.362472}{-\ldots .362472+0.402487+0.471005+0.34695}$ 


$$
\begin{aligned}
& \mathrm{V} 2=\frac{0.402487}{0.362472+0.402487+0.471005+0.34695}
\end{aligned}
$$

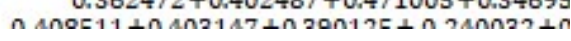

$$
\begin{aligned}
& \mathrm{V} 3=\frac{0.471005}{0.362472+0.402487+0.471005+0.34695} \\
& \mathrm{~V} 4=\frac{0.346952}{0.362472+0.402487+0.471005+0.34695} \\
& \mathrm{~V} 5=\frac{0.408511}{0.362472+0.402487+0.471005+0.3469} \\
& \text { ก } \Delta \cap R 511+\cap \Delta \cap 3147+\cap 39 \cap 125+\cap 2 \Delta \cap \cap 32+ \\
& \text { V6 }=\frac{0.403147}{0.362472+0.402487+0.47100} \\
& \text { ก AnกrA4 in } 0.362472+0.402487+0.471005+0.34695 \\
& \mathrm{~V} 7=\frac{0.390125}{0.362472+0.402487+0.47100} \\
& \text { (1) } \\
& \mathrm{V} 8=\frac{0.240032}{0.362472+0.402487+0.471005+0.34695}
\end{aligned}
$$

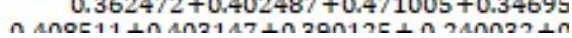

$$
\begin{aligned}
& \mathrm{V} 9=\frac{0.254908}{0.362472+0.402487+0.471005+0.34695}
\end{aligned}
$$

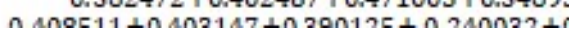

$$
\begin{aligned}
& \mathrm{V} 10=\frac{0.511601}{n \Delta \cap 8511+n \Delta \cap 2.402+n 87+0.471005+0.346 !}
\end{aligned}
$$

Berikut ini adalah hasil penetapan dan perangkingan rekomendasi bentuk dan ukuran stempel di Toko Rahmad Jaya.

Tabel 8. Hasil penetapan dan urutan peringkat

\begin{tabular}{|c|c|c|}
\hline Alternatif & Hasil & Peringkat \\
\hline V1 & 0.0956078267 & 7 \\
\hline V2 & 0.1061622974 & 5 \\
\hline V3 & 0.1242350034 & 2 \\
\hline V4 & 0.0915141105 & 8 \\
\hline V5 & 0.1077513236 & 3 \\
\hline V6 & 0.1063365354 & 4 \\
\hline V7 & 0.1029016571 & 6 \\
\hline V8 & 0.0633123210 & 10 \\
\hline V9 & 0.0672360016 & 9 \\
\hline V10 & 0.1349429233 & 1 \\
\hline
\end{tabular}

Jadi kesimpulan dari hasil perangkingan rekomendasi bentuk dan ukuran stempel adalah terdapat pada alternative V10, V3 dan V5. Berikut adalah kesimpulan dari tabel rekomendasi bentuk dan ukuran stempel.

Tabel 9. Tabel Kesimpulan

\begin{tabular}{|l|l|c|c|l|l|l|}
\hline A(i) & C1 & C2 & C3 & C4 & Total & Ke- \\
\hline V10 & Cepat & 12.000 & TB & B & 0,134 & 1 \\
\hline V3 & Cepat & 16.000 & TT & E & 0,124 & 2 \\
\hline V5 & Sedang & 20.000 & TB & H & 0,107 & 3 \\
\hline
\end{tabular}

\section{HASIL DAN PEMBAHASAN}

\subsection{Implementasi Tampilan Sistem}

Pada program aplikasi perhitungan untuk rekomendasi bentuk stempel dengan menggunakan metode Weight Product, terdiri dari beberapa halaman, diantaranya sebagai berikut :

\subsection{Halaman Dashboard}

Pada halaman dashboard ini berisi tentang beberapa gambar rekomendasi stempel yang akan direkomendasikan.

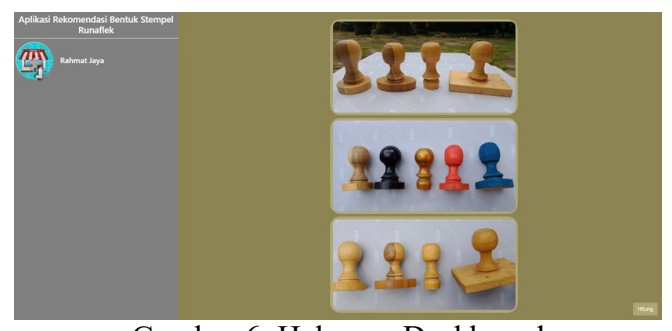

Gambar 6. Halaman Dashboard

\subsection{Halaman Input Nilai Kriteria}

Halaman Input Nilai Kriteria merupakan halaman yang menampilkan beberapa opsi yang ditujukan untuk user, dimana user akan memilih bobot yang diinginkan dan akan di-submit serta dihitung agar mengeluarkan hasil perangkingan rekomendasi stempel. Jika user tidak ingin meneruskan transaksi maka akan klik tombol "batal" di pojok kiri bawah.

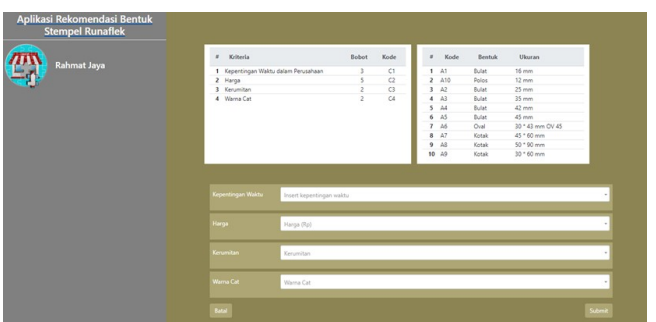

Gambar 7. Halaman Input Nilai Kriteria

\subsection{Halaman Hasil Perhitungan Nilai Setiap Kriteria}

Halaman hasil perhitungan nilai setiap kriteria merupakan halaman yang menampilkan hasil seleksi bentuk stempel berdasarkan perhitungan dengan metode Weight Product.

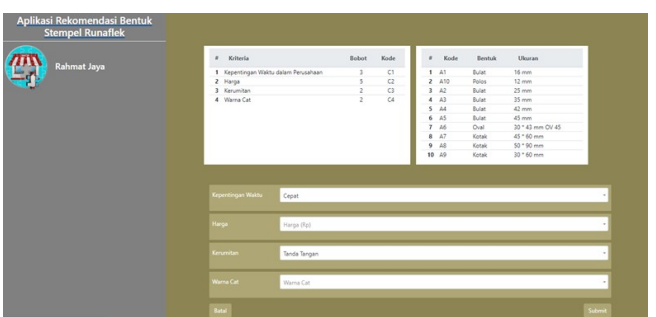

Gambar 8. Halaman Hasil Perhitungan Nilai Setiap Kriteria 


\subsection{Halaman Hasil Perangkingan}

Halaman hasil perangkingan adalah halaman yang menyajikan hasil perangkingan dari alternatif-alternatif yang dipilih.

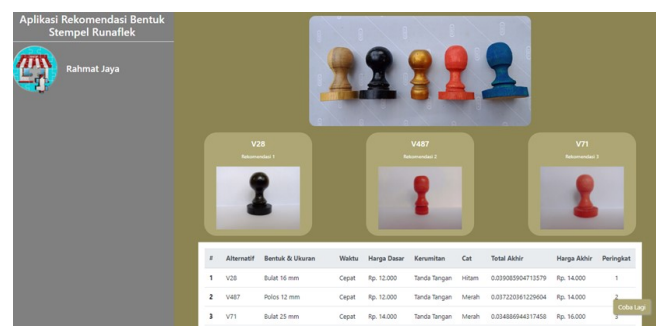

Gambar 9. Halaman Hasil Perangkingan

\subsection{Implementasi Metode Weight Product}

Berikut ini adalah Source Code perhitungan Weight Product. Source Code proses perhitungan pada aplikasi sistem perhitungan untuk rekomendasi bentuk stempel dengan menggunakan metode Weight Product.

a. Pembobotan

Melakukan pembobotan nilai setiap kriteria.

\section{// pembobotan}

\$bobot ["c1"] = round (3 / 12, 2);

\$bobot ["c2"] = round $(-5 / 12,2)$;

\$bobot ["c3"] = round $(-2 / 12,2)$;

\$bobot $[" c 4 "]=\operatorname{round}(2 / 12,2)$;

Gambar 10. Source Code Pembobotan

b. Perhitungan Nilai Vektor s

Melakukan rekapitulasi nilai V(s) dengan cara memangkatkan seluruh nilai pada setiap kriteria terhadap bobot telah ditentukan, kemudian dikalikan hasilnya.

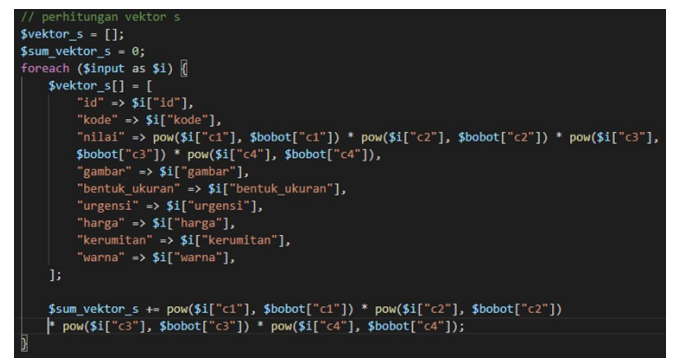

Gambar 11. Source Code Perhitungan Nilai Vektor s

c. Perhitungan Vektor v

Melakukan perhitungan nilai vektor $\mathrm{v}$ dengan cara nilai preferensi S1 pada hasil sebelumnya di bagi dengan nilai keseluruhan sebelumnya.

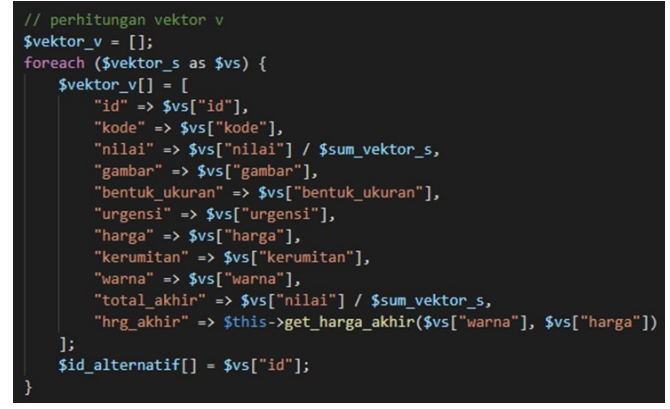

Gambar 12. Source Code Perhitungan Vektor v

\section{d. Perangkingan}

Melakukan perangkingan alternatif dimana nilai yang lebih hasilnya lebih banyak menunjukkan alternatif tersebut lebih baik untuk dipilih.

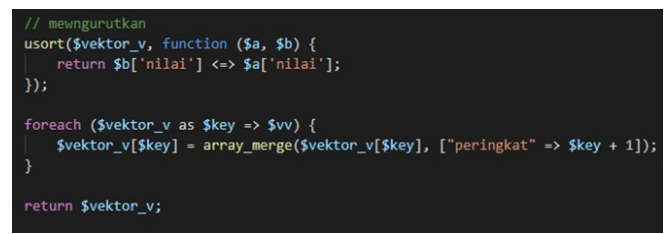

Gambar 13. Source Code Perangkingan

\subsection{Pengujian Blackbox Testing}

Tabel 9. Pengujian Fungsi Dashboard

\begin{tabular}{|c|c|c|c|}
\hline $\begin{array}{c}\text { Hal yang } \\
\text { Dilakukan }\end{array}$ & Pengujian & $\begin{array}{c}\text { Kondisi } \\
\text { yang } \\
\text { Diinginkan }\end{array}$ & $\begin{array}{c}\text { Hasil } \\
\text { Pengujian }\end{array}$ \\
\hline $\begin{array}{c}\text { Klik tombol } \\
\text { "hitung"di } \\
\text { pojok kanan } \\
\text { bawah }\end{array}$ & $\begin{array}{c}\text { Menampilkan } \\
\text { halaman input } \\
\text { nilai kriteria }\end{array}$ & $\begin{array}{c}\text { Halaman } \\
\text { input nilai } \\
\text { kriteria } \\
\text { tampil }\end{array}$ & Berhasil \\
\hline
\end{tabular}

Tabel 10. Pengujian Fungsi Input Nilai Kriteria

\begin{tabular}{|c|c|c|c|}
\hline $\begin{array}{l}\text { Hal yang } \\
\text { Dilakukan }\end{array}$ & Pengujian & $\begin{array}{c}\text { Kondisi yang } \\
\text { Diinginkan }\end{array}$ & \begin{tabular}{|c|} 
Hasil \\
Pengujian
\end{tabular} \\
\hline $\begin{array}{c}\text { Input } \\
\text { kepentingan }\end{array}$ & $\begin{array}{c}\text { Pilih } \\
\text { kepentingan } \\
\text { waktu }\end{array}$ & $\begin{array}{l}\text { Data kepentingan } \\
\text { waktu berhasil di } \\
\text { klik }\end{array}$ & Berhasil \\
\hline $\begin{array}{l}\text { Input harga } \\
\text { (Rp) }\end{array}$ & $\begin{array}{l}\text { Pilih harga } \\
(\mathrm{Rp})\end{array}$ & $\begin{array}{c}\text { Data harga } \\
\text { berhasil di klik }\end{array}$ & Berhasil \\
\hline $\begin{array}{l}\text { Input bobot } \\
\text { kerumitan }\end{array}$ & $\begin{array}{l}\text { Pilih bobot } \\
\text { kerumitan }\end{array}$ & $\begin{array}{c}\text { Data bobot } \\
\text { kerumitan } \\
\text { berhasil di klik }\end{array}$ & Berhasil \\
\hline $\begin{array}{c}\text { Input warna } \\
\text { cat }\end{array}$ & $\begin{array}{c}\text { Pilih warna } \\
\text { cat }\end{array}$ & $\begin{array}{l}\text { Data warna cat } \\
\text { berhasil di klik }\end{array}$ & Berhasil \\
\hline Klik submit & $\begin{array}{l}\text { Menampilkan } \\
\text { halaman hasil } \\
\text { perhitungan } \\
\text { nilai setiap } \\
\text { kriteria }\end{array}$ & \begin{tabular}{|c|} 
Halaman hasil \\
perhitungan nilai \\
setiap kriteria
\end{tabular} & Berhasil \\
\hline Klik batal & $\begin{array}{c}\text { Menampilkan } \\
\text { halaman } \\
\text { sebelumnya } \\
\text { yaitu halaman } \\
\text { utama }\end{array}$ & $\begin{array}{c}\text { Halaman } \\
\text { sebelumnya } \\
\text { ditampilkan }\end{array}$ & Berhasil \\
\hline
\end{tabular}


Tabel 11. Pengujian Hasil Perhitungan Nilai Setiap Kriteria

\begin{tabular}{|c|c|c|c|}
\hline $\begin{array}{c}\text { Hal yang } \\
\text { Dilakukan }\end{array}$ & Pengujian & $\begin{array}{c}\text { Kondisi } \\
\text { yang } \\
\text { Diinginkan }\end{array}$ & $\begin{array}{c}\text { Hasil } \\
\text { Pengujian }\end{array}$ \\
\hline $\begin{array}{c}\text { Klik } \\
\text { tombol } \\
\text { batal }\end{array}$ & $\begin{array}{c}\text { Menampilkan } \\
\text { halaman } \\
\text { sebelunya } \\
\text { yaitu halaman } \\
\text { utama }\end{array}$ & $\begin{array}{c}\text { Halaman } \\
\text { sebelumnya } \\
\text { ditampilkan }\end{array}$ & Berhasil \\
\hline $\begin{array}{c}\text { Klik } \\
\text { tombol } \\
\text { submit }\end{array}$ & $\begin{array}{c}\text { Menampilkan } \\
\text { halaman hasil } \\
\text { perangkingan }\end{array}$ & $\begin{array}{c}\text { Halaman } \\
\text { hasil } \\
\text { perangkingan } \\
\text { tampil }\end{array}$ & Berhasil \\
\hline
\end{tabular}

Tabel 12. Pengujian Hasil Perangkingan

\begin{tabular}{|c|c|c|c|}
\hline $\begin{array}{c}\text { Hal yang } \\
\text { Dilakukan }\end{array}$ & Pengujian & $\begin{array}{c}\text { Kondisi } \\
\text { yang } \\
\text { Diinginkan }\end{array}$ & $\begin{array}{c}\text { Hasil } \\
\text { Pengujian }\end{array}$ \\
\hline $\begin{array}{c}\text { Klik } \\
\text { tombol } \\
\text { coba lagi }\end{array}$ & $\begin{array}{c}\text { Menampilkan } \\
\text { insert data } \\
\text { pada halaman } \\
\text { input nilai } \\
\text { kriteria }\end{array}$ & $\begin{array}{c}\text { Halaman } \\
\text { input nilai } \\
\text { kriteria } \\
\text { tampil }\end{array}$ & Berhasil \\
\hline
\end{tabular}

Untuk mengetahui presentasae total keberhasilan pengujian fungsi pada halaman hasil perangkingan dilakukan perhitungan sebagai berikut:

Persentasi fungsi halaman total hasil perangkingan $=$ $10 / 10 \times 100 \%=100 \%$. Jadi hasil pengujian fungsi halaman hasil perangkingan adalah 100\%. Data hasil presentase dapat dicocokkan dengan pedoman Interprestasi Skor untuk mengetahui seberapa baik aplikasi yang telah dibuat. Berikut adalah pedoman Interprestasi Skor :

Tabel 13. Pedoman Interprestasi Skor Setelah Dikonversi

\begin{tabular}{|c|l|}
\hline Angka (dalam \%) & \multicolumn{1}{|c|}{ Klasifikasi } \\
\hline $0-10$ & Sangat Tidak Baik \\
\hline $21-40$ & Tidak Baik \\
\hline $41-60$ & Cukup Baik \\
\hline $61-80$ & Baik \\
\hline $81-100$ & Sangat Baik \\
\hline
\end{tabular}

Jadi dapat disimpulkan bahwa hasil dari pengujian Blacbox Testing ini sudah sesuai dengan apa yang diharapkan.

\section{KESIMPULAN DAN SARAN}

\subsection{Kesimpulan}

Berikut ini adalah beberapa kesimpulan dari peneliti :

1. Pada penelitian sistem ini bertujuan untuk menentukan rekomendasi bentuk stempel menggunakan metode Weight Product. Pada metode ini terdapat sejumlah hal yang harus dilakukan sebelum menyimpulkan hasil perangkingan dengan benar, yaitu menentukan nilai bobot kriteria, selanjutnya menghitung nilai $\mathrm{V}(\mathrm{s})$, lalu menghitung nilai $\mathrm{V}(\mathrm{v})$, setelah itu akan muncul perangkingan. Langkah selanjutnya yaitu membuat aplikasi dengan menggunakan framework codeigniter. Setelah aplikasi jadi akan diujikan menggunakan pengujian blackbox testing. Pengimplementasian aplikasi sistem pendukung keputusan penentu rekomendasi stempel ini dilakukan oleh admin yang meminta keputusan kepada user dengan cara memilih beberapa kriteria yang sudah tercantum pada aplikasi kemudian akan muncul beberapa rekomendasi stempel.

2. Pada penelitian ini dilakukan pengujian pada aplikasi apakah aplikasi layak digunakan atau tidak dangan menggunakan pengujian blackbox testing. Selanjutnya dilakukan pengujian aplikasi terhadap pengguna dan 2 Dosen Teknik Informatika. Hasil pengujian menggunkan black box testing ini memperoleh nilai akhir 100\%. Pada hasil akhir tersebut membuktikan hasil penilaian termasuk dalam kategori "sangat baik" dan hasil pengujian terhadap pengguna dan 2 dosen Teknik Informatika menghasilkan hasil presentase $50 \%$ yang berarti netral dan $40 \%$ yang berarti setuju.

\subsection{Saran}

Berikut ada beberapa saran yang peneliti berikan untuk penelitian berikutnya yaitu:

1. Pada penelitian ini masih terdapat banyak kekurangan mungkin untuk ke depannya bisa dikembangkan menjadi lebih baik lagi. Misalnya menambahkan fungsi login agar tetap aman menyimpan data.

2. Pada pengujian aplikasi ini peneliti memakai dua pengujian yaitu menggunakan pengujian blackbox testing. Selanjutnya dilakukan pengujian aplikasi terhadap pemilik usaha dan pengguna. Peneliti berharap agar penelitian selanjutnya dapat menambahkan pengujian yang lainnya.

\section{DAFTAR PUSTAKA}

[1] Noviantoro, R. W., Lestanti, S., \& Keputusan, S. P. (2020). Penentuan Tarif Jasa Lukis Dengan Menerapkan Metode. 3(2), 7-14.Ding, K. and Jiang, P., 2017. RFID-based production data analysis in an IoT-enabled smart job-shop. IEEE/CAA Journal of Automatica Sinica.

[2] Atmojo, R. T., Purabaya, R. H., Wahyono, B. T., Pembangunan, U., Veteran, N., Labu, P., Selatan, J., Berprestasi, D., \& Product, M. W. (2020). Sistem Pendukung Keputusan Pemilihan Dosen Berprestasi Dengan Menggunakan Metode Wp ( Weighted Product ) di Universitas Pembangunan Nasional Veteran. 260-273.

[3] Ridho, M. R. (2021). Rancang Bangun Sistem Informasi Point Of Sale Dengan Framework Codeigniter Pada Cv Powershop. Jurnal Comasie. 